\title{
Pathology of cervical intervertebral disc injuries
}

\author{
H Kinoshita MD
}

Director, Kosei Hospital, Hiroshima, Japan.

\begin{abstract}
Autopsy was performed on 31 patients with traumatic spinal cord injuries who were treated and expired at the Chugoku Rosai Hospital between 1957 and 1987. These patients could be divided into four groups: intervertebral disc injuries ( 7 patients); hyperextension injuries ( 9 patients); fracture and fracturedislocation of the cervical spine (11 patients); and fracture-dislocation of the thoracic spine (4 patients). The sex, age, cause of injury, bone injuries seen on roentgenograms, the level and grade of neurological deficits, the survival time, and the findings of the postmortem studies of the 7 patients with intervertebral disc injuries are presented in Table I. This paper illustrates and discusses these 7 cases.
\end{abstract}

Keywords: pathology of spinal cord injuries; cervical spine; intervertebral disc injuries.

\section{Methods}

The vertebral column was removed en bloc from behind soon after the patient expired. Macroscopic examination was made not only of the bone injury but also of the injury to the soft tissue surrounding the vertebrae.

The lateral and anteroposterior radiographs of the resected vertebral column were obtained together with those of the resected vertebral column under forced anteflexion, retroflexion, and flexion with rotation. These were then compared with those taken at the time of the initial examination of the patient.

The vertebral bodies, spinous processes, and neural arches were sawn longitudinally along the midline in such a way as to leave the spinal cord intact. After the cut surfaces were examined, the dura mater was opened. The arachnoid space and the nerve roots were macroscopically observed. Following palpation to examine the site and extent of the spinal cord injury based on the consistency of the spinal cord, the pia mater and the spinal cord were cut longitudinally. The pathological findings related to the bone injuries and the cord lesions were compared macroscopically. The spinal cord was fixed

Correspondence: $\mathrm{H}$ Kinoshita MD, 86-2 Ichiida, Kurose-cho, Kamo-gun, Hiroshima-ken 724-06, Japan. in $10 \%$ formalin solution, and then microscopic studies were made after hematoxylin and Kluver Barrera staining of the slides.

\section{Case reports}

\section{Case 1}

A 55 year old man was hit on his head from behind by a falling tree and was admitted to our hospital on the same day. Roentgenograms showed narrowing of the intervertebral disc space at C3-4.

$\mathrm{He}$ had immediately become tetraplegic below C6, and died 11 days later despite extensive respiratory resuscitative management.

Autopsy revealed slight instability of the cervical column between $\mathrm{C} 3$ and $\mathrm{C} 4$ in the flexion extension test. The anterior and posterior longitudinal ligaments were not ruptured, and there was no evidence of subluxation. The C3-4 intervertebral disc was ruptured and was discoloured brown. When vertical compression was applied to the resected cervical column, the intervertebral disc bulged slightly dorsally but was not extruded. Exactly opposite to the disc rupture, a small cavity was found in the spinal cord.

\section{Case 2}

A 55 year old man was transferred to our hospital from another hospital 4 months after a motorcycle accident. Roentgenograms showed 
no evidence of bone injury, but he was completely paralysed from $\mathrm{C} 5$ caudally. He died from pneumonia a month later.

Autopsy did not reveal any fracture or rupture of the posterior longitudinal, capsular, or interspinal ligaments. Manipulation of the resected cervical spine could not demonstrate any abnormal mobility of the bodies of the cervical vertebrae. There was a rupture of the anterior longitudinal ligament and a transverse cleft in C3-4 intervertebral disc. The thin membrane detached from the posterior longitudinal ligament bulged dorsally.

The spinal cord had been completely severed at the corresponding site, and contained several small cavities localised within a limited area of $5 \mathrm{~mm}$ in length (Fig 1).

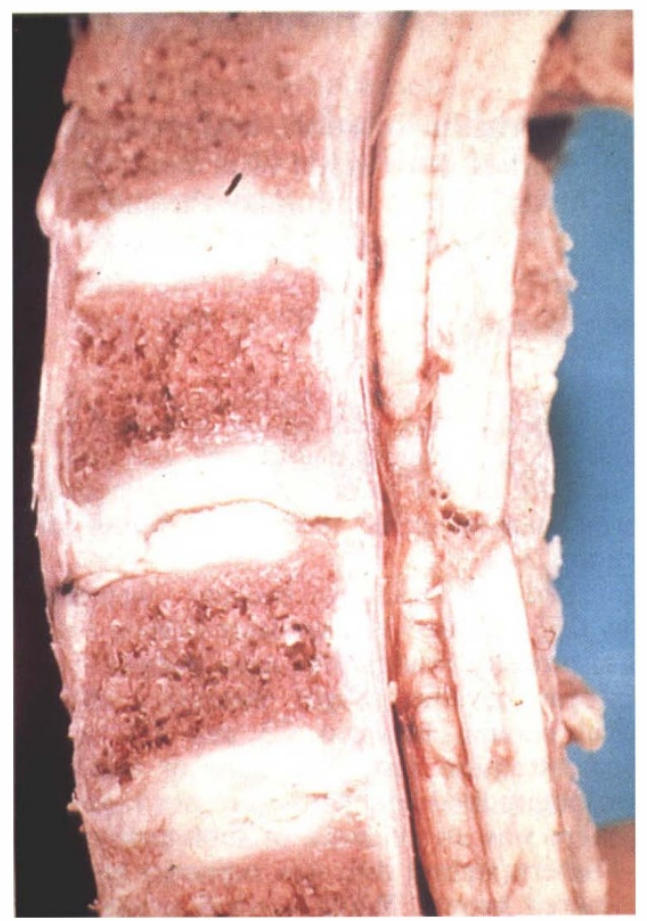

Figure 1 Case 2. Hemisection of the cervical spine of a 55 year old man who was injured in a motorcycle accident. Complete rupture of the anterior longitudinal ligament and intervertebral disc together with detachment of the thin membrane from the intact posterior longitudinal ligament can be seen. The spinal cord is completely severed at the corresponding site.

\section{Case 3}

The case is 58 year old man. A brief description of the case is presented in Table I.

\section{Case 4}

A 50 year old man had a motorcyle accident and sustained incomplete spinal paralysis of grade C of Frankel's classification. He died of renal failure 31 months after the injury.

$\mathrm{He}$ had been able to move his right hip, knee, ankle and toes. Roetgenograms demonstrated the presence of a 'hard disc' at C6-7 (Fig $2 \mathrm{a})$. The spinal cord was compressed by a very large osteophyte at the level of the C6-7 intervertebral disc, and had become thin and soft (Fig 2b).

At the corresponding level, multiple small cavities were observed in the centre of the spinal cord. The rim of the white matter was well preserved around the cavity. The nerve fibres transversed the gap and ran into the wall of the cystic cavity (Fig 2c).

\section{Case 5}

A 73 year old man fell from a height of 3 metres and struck his head and right shoulder. $\mathrm{He}$ immediately became tetraplegic except for preservation of tactile sensation. He was graded B of Frankel's classification. No significant traumatic findings could be observed on the roentgenograms, but rupture of the $\mathrm{C} 3-4$ disc was observed in the postmortem examination. The spinal cord had become thin and soft and a small cavity $0.5 \mathrm{~cm}$ in diameter was evident. (Fig 3).

\section{Case 6}

A 58 year old man fell from a height of 3 metres and struck his head and shoulder. He became tetraplegic immediately at $\mathrm{C} 5$ and was admitted to our hospital on the same day.

Roentgenograms revealed partial dislocation of C3-4 and fracture of the spinal process of C3. Reduction was possible by skull traction of $3 \mathrm{~kg}$.

On the 19th day of traction, tactile sensation was restored to both thighs together with bilateral patellar tendon reflexes and a left Achilles tendon reflex. But the patient died 7 weeks later from pneumonia. Autopsy findings clearly suggested the positive effects of traction for the recovery of paralysis.

When vertical pressure was applied to the cervical spine, the disc protruded dorsally (Fig $4 a)$ and when the traction increased the tension 
Table I Cervical intervertebral disc injuries

\begin{tabular}{|c|c|c|c|c|c|c|c|c|c|c|c|c|}
\hline \multirow{2}{*}{$\begin{array}{l}\text { Case } \\
\text { no }\end{array}$} & \multirow{2}{*}{ Age } & \multirow[t]{2}{*}{ Sex } & \multirow{2}{*}{$\begin{array}{l}\text { Cause of } \\
\text { injury }\end{array}$} & \multirow[t]{2}{*}{ Roentgenogram } & \multirow{2}{*}{$\begin{array}{l}\text { Level and grade } \\
\text { of paralysis }\end{array}$} & \multirow{2}{*}{$\begin{array}{l}\text { Survival } \\
\text { time }\end{array}$} & \multicolumn{4}{|c|}{ Tissues involved } & \multirow{2}{*}{$\begin{array}{l}\text { Macroscopic features } \\
\text { and the extent of spinal } \\
\text { damage }\end{array}$} & \\
\hline & & & & & & & ALL & PLL & ISL & Disc & & \\
\hline 1 & 55 & $\mathbf{M}$ & $\begin{array}{l}\text { Contusion to } \\
\text { back of head }\end{array}$ & C3-4 narrowing & C6 complete & 11 days & - & - & + & + & $\begin{array}{l}\text { Cavitation of small } \\
\text { necrotic foci }\end{array}$ & $0.5 \mathrm{~cm}$ \\
\hline 2 & 55 & $\mathbf{M}$ & $\begin{array}{l}\text { Fall from } \\
\text { motorcycle }\end{array}$ & - & C5 complete & 5 months & - & - & - & + & $\begin{array}{l}\text { Complete severance, } \\
\text { small cavities }\end{array}$ & $0.5 \mathrm{~cm}$ \\
\hline 3 & 58 & M & Fall & - & C6 incomplete & 19 months & - & - & - & + & Rice grain sized cavity & $0.3 \mathrm{~cm}$ \\
\hline 4 & 50 & $\mathrm{M}$ & $\begin{array}{l}\text { Fall from } \\
\text { motorcycle }\end{array}$ & C6-7 hard disc & C8 incomplete & 31 months & - & - & - & + & Small cavity & $0.8 \mathrm{~cm}$ \\
\hline 5 & 73 & $\mathbf{M}$ & Fall & - & C5 incomplete & 8 months & - & - & - & + & Small cavity & $0.5 \mathrm{~cm}$ \\
\hline 6 & 58 & $\mathrm{M}$ & Fall & $\begin{array}{l}\text { C3-4 sub- } \\
\quad \text { luxation } \\
\text { Fracture of C3 } \\
\text { spinal process }\end{array}$ & C5 incomplete & 7 weeks & - & - & + & + & $\begin{array}{l}\text { Extruded disc, small } \\
\text { cavity }\end{array}$ & $2.0 \mathrm{~cm}$ \\
\hline 7 & 66 & $\mathbf{M}$ & Fall & $\begin{array}{l}\text { C4-5 sub- } \\
\text { luxation }\end{array}$ & C6 complete & 6.5 weeks & - & + & - & + & $\begin{array}{l}\text { Extruded disc, } \\
\text { softening, atrophy }\end{array}$ & $5.5 \mathrm{~cm}$ \\
\hline
\end{tabular}

$\mathrm{M}=$ male; $\mathrm{ALL}=$ anterior longitudinal ligament; $\mathrm{PLL}=$ posterior longitudinal ligament; $\mathrm{ISL}=$ interspinal ligament. 
a

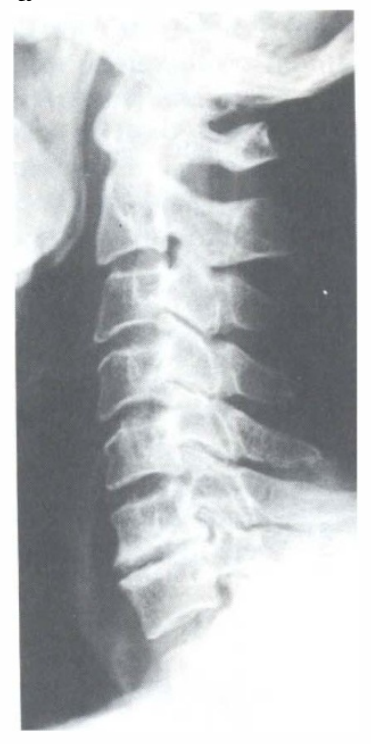

c

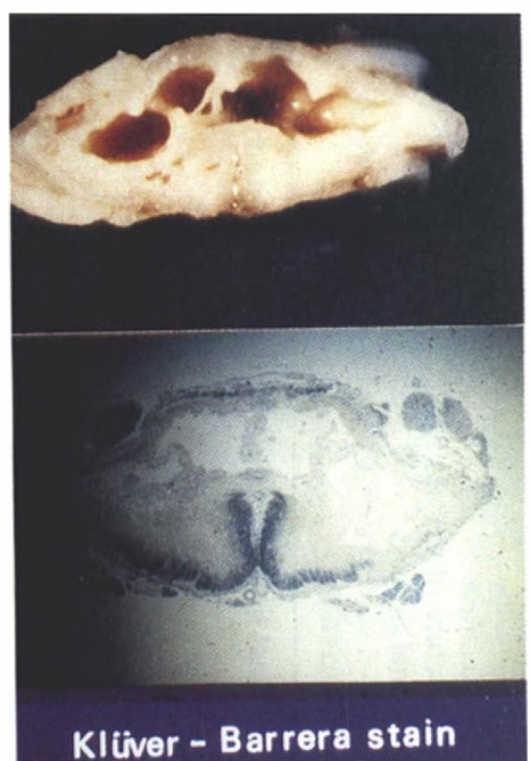

Figure 2 Case 4. (a) Latereral roentgenogram shows posterior ridging, corresponding to the disc degeneration at C6-7. (b) Hemisection of the cervical spine and the right side of the spinal cord. The spinal cord is constricted by the ridging and is thin and soft. (c) Cross section of the spinal cord at the constricted site. There are multiple cavities in the cord parenchyma. Microscopically, the rim of the white matter is preserved around the cavities and very few myelinated fibres are observed at the periphery of the lesion.

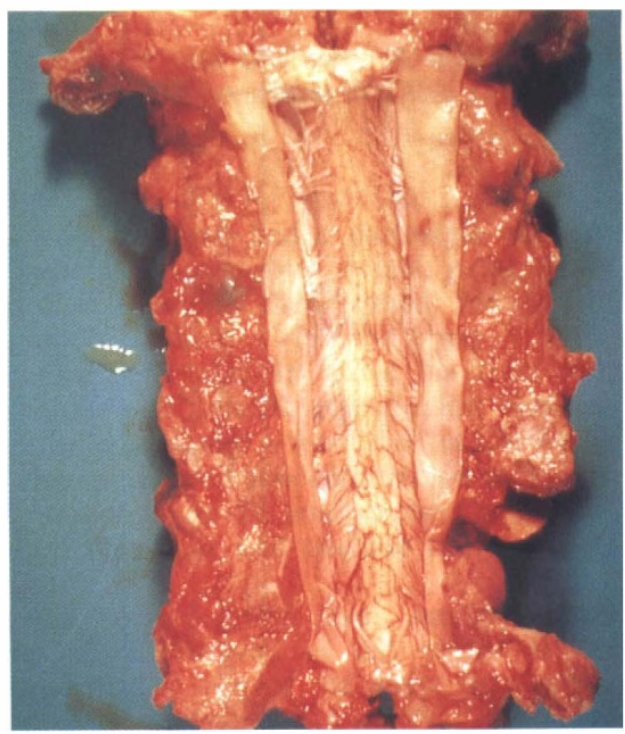

Figure 3 Case 5 . The spinal cord is constricted and softened at $\mathrm{C} 3-4$, where the intervertebral disc has ruptured.

of the posterior longitudinal ligament, the protrusion disappeared (Fig 4b).

\section{Case 7}

A 66 year old man fell from a height of 2 metres and struck his occipital region, becoming immediately tetraplegic with a level at C6.

Roentgenograms revealed subluxation of C4-5. Skull traction was immediately applied and the skeletal displacement was reduced, but the patient did not recover from the complete tetraplegia, and died 6.5 weeks thereafter (Fig $5 \mathrm{a})$. Rupture of the $\mathrm{C} 4-5$ intervertebral disc and the posterior longitudinal ligament was discovered at autopsy. Disc debris which had retropulsed into the spinal canal had damaged the spinal cord (Fig 5b).

Due to rupture of the posterior longitudinal ligament, traction was not beneficial and the complete paralysis persisted. It may be possible by magnetic resonance imaging to demonstrate disc fragments and rupture of the posterior longitudinal ligament. Good results may be expected by early surgical decompression.

\section{Discussion}

A sound knowledge of the pathology of spinal injuries is an essential prerequisite for 
a

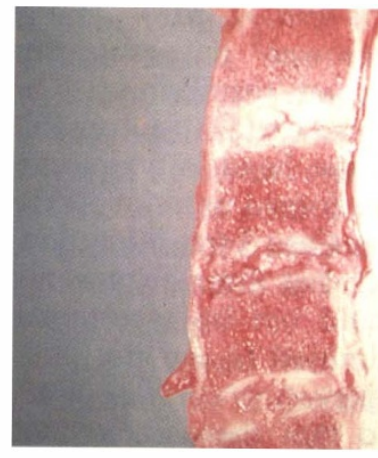

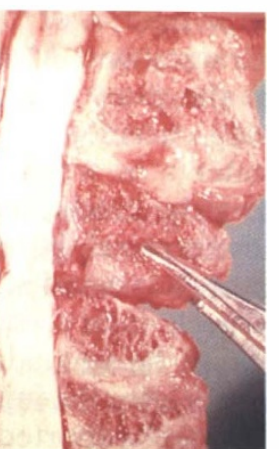

b

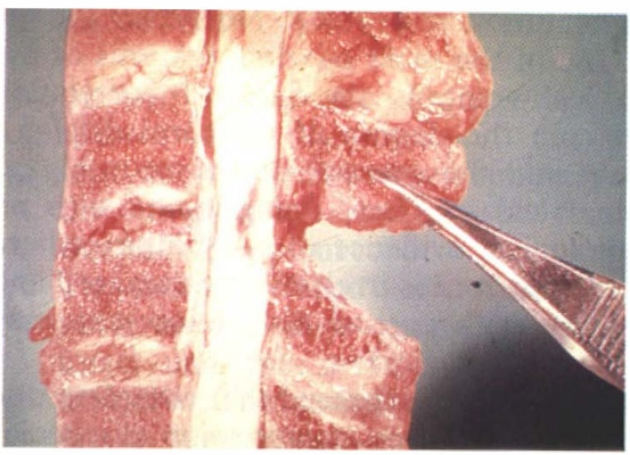

Figure 4 Case 6. (a) When vertical pressure is applied to the cervical spine, the disc protrudes dorsally and compresses the spinal cord. (b) When traction is increased, the dorsal protrusion disappears due to tension of the posterior longitudinal ligament.

a

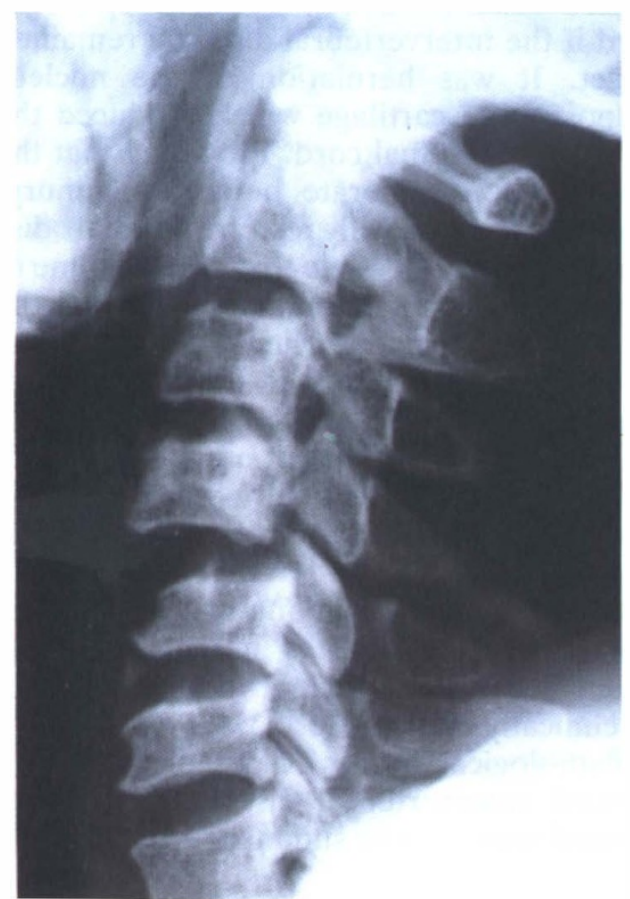

b

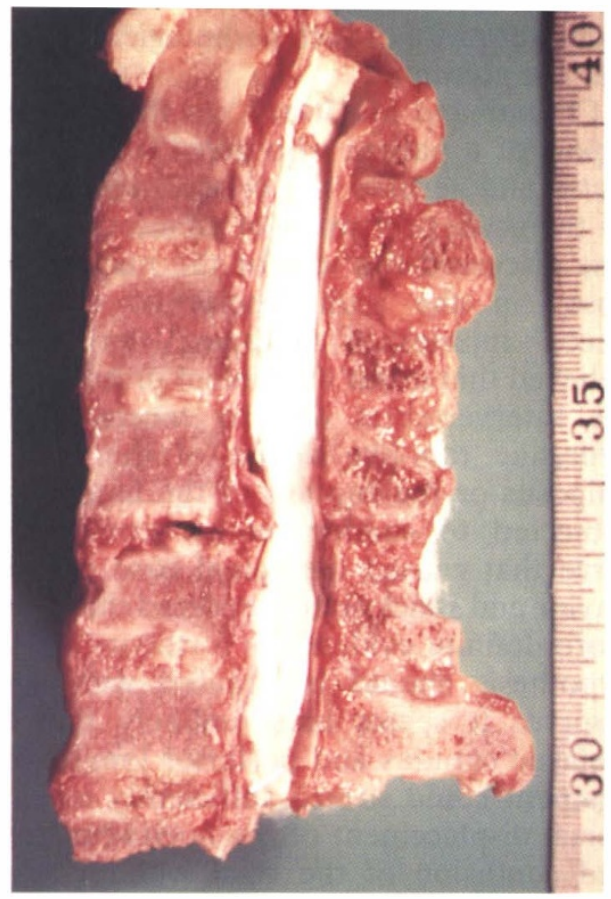

Figure 5 Case 7. (a) Lateral roentgenogram shows subluxation of $\mathrm{C} 4-5 \cdot \mathrm{C}_{4}$ is displaced slightly forwards onto $\mathrm{C} 5$. (b) Rupture of $\mathrm{C} 4-5$ intervertebral disc and posterior longitudinal ligament can be observed. These ruptured substances retroplused into the spinal canal and damaged the spinal cord. The injury to the spinal cord is almost the same as was seen in Figure 4a. However, skull traction was not beneficial because of the fragments of the degenerate disc and the rupture of the posterior longitudinal ligament. 
the competent management of patients with such injuries. ${ }^{1}$

One of the most puzzling features of the cervical spine is the lack of correlation between the degree of vertebral displacement and the severity of the neurological spinal lesion. There are patients with no radiological evidence of bony injury where the spinal cord is irretrievably damaged and patients with a gross dislocation who may not be paraplegic. ${ }^{2}$

Bedbrook $^{3}$ recognized that complete disc extrusions causing compression do occur. However, such patients rarely come to postmortem.

Barnes $^{2}$ described 3 patients with spinal cord injuries due to acute intervertebral disc retropulsion caused by forcible flexion of the head onto the trunk. His diagnosis was based on the narrowing of one intervertebral disc, lack of radiological evidence of bony injury, the arrest of lipiodol on myelography, and the findings at laminectomy. However proof of such pathological changes was not presented.

Cramer and $\mathrm{McGowan}^{4}$ in their autopsy report of a patient who dived into shallow water and severed the cervical spinal cord by the acute protrusion of an intervertebral disc discussed the role of the nucleus pulposus in the pathogenesis of so-called 'recoil' injuries of the spinal cord. They believed that it was the violent protrusion of the intervertebral disc by means of the hydraulic ram-like action of the nucleus pulposus or the rupture of the latter when subjected to sudden intense compressive force that caused the spinal cord damage. Taylor and Blackwood ${ }^{5}$ reported that unless more definite evidence is forthcoming, this hypothesis should be treated with some reserve. It seems most unlikely that the inelastic annulus and posterior longitudinal ligament could stretch sufficiently to allow dorsal displacement of the nuclear material and contusion of the cord without actual rupture. No evidence has been available from autopsy studies.

Case 3 illustrates complete transection of the spinal cord from sudden severe traumatic prolapse of the intervertebral disc by the projectile force of the compressed nucleus. The author is of the belief that this patient illustrates definite evidence of 'recoil' injuries of the spinal cord.

Cramer and McGowan $^{4}$ have suggested that the usual causes of 'recoil' injuries are diving accidents or certain automobile accidents in which the head is whiplashed forwards, producing forced anterior flexion of the cervical spine. Case 3 was injured in a motorcycle accident, but the mechanism of his neck injury could not be ascertained, because he was admitted to our hospital 5 months after the injury.

Barnes $^{2}$ reported that there is no tendency for the disc to herniate into the spinal canal in hyperextension injuries. In this series, there was no protrusion of the disc material into the spinal canal in 9 patients with hyperextension injuries nor in 12 patients with a fracture and fracturedislocation of the cervical spine.

The dislocation of the vertebral body in cases 6 and 7 was slight and should have caused little or no impingement upon the cord if the intervertebral disc had remained intact. It was herniation of the nucleus pulposus and cartilage which produced the injury to the spinal cord. Providing that the disc is not degenerate before the injury, caliper traction will restore normal disc height, and it is possible that at least some of the substance may find its way back into the intervertebral space. The autopsy findings of case 6 clearly illustrate the reduction of the disc herniation and the positive effect of traction on the recovery of paralysis.

The spinal cord section of case 4 revealed necrosis of the central portion and several cavities. There were a few myelinated fibres in the white matter surrounding the cavities. This case demonstrates how only a few intact fibres are sufficient for the lesion to be clinically incomplete. ${ }^{1}$

Pathological studies of paraplegia due to cervical intervertebral disc injuries in the cervical spine can be summarised as follows.

\section{Five patients with cervical intervertebral disc injuries \\ 1 The 3 with a known injury history had had a flexion injury.}


2 Radiologically, there was no evidence of bony injury.

3 The lesion was stable without any injury to the anterior or posterior longitudinal ligaments or to the posterior ligament complex.

4 The spinal cord corresponding to the ruptured disc became thin and soft with the formation of small cavities from an early stage.

5 No patient had occlusion and/or thrombosis of the anterior spinal artery and/or veins.

6 The lesion was localised to a small area
$(0.3 \sim 0.5 \mathrm{~cm})$, with many patients having partial paralysis (Table I).

Two patients with cervical disc injuries complicated with subluxation

1 Disc debris which had retropulsed into the spinal canal damaged the ventral aspect of the spinal cord.

2 The posterior longitudinal ligament or posterior ligament complex was ruptured and the cervical column was unstable. The spinal cord lesion was severe and extensive $(2.0 \sim 5.5 \mathrm{~cm})$ (Table I).

\section{References}

1 Kakulus BA (1984) Pathology of spinal injuries. Cent Nerv Sys Trauma 1: 117-128.

2 Barnes R (1948) Paraplegia in cervical spinal injuries. J Bone Joint Surg 30B: 234-244.

3 Bedbrook GM (1966) Pathological principles in the treatment of spinal cord trauma. Paraplegia 4: 43-56.

4 Cramer F, McGowan FJ (1944) The role of nucleus pulposus in the pathogenesis of so-called 'recoil' injuries of the spinal cord. Surg Gynec Obstet 79: 516-521.

5 Taylor AR, Blackwood W (1948) Paraplegia in hyperextension cervical injuries with normal radiographic appearance. J Bone Joint Surg 30B: 245-248. 